\title{
The Undergraduate Education of Removable Prosthodontics: A Comparison between the University of Birmingham (United Kingdom) and the University of Tokushima (Japan)
}

\author{
Kan Nagao, DDS, PhD, ${ }^{a}$ Tetsuo Ichikawa, DDS, PhD, ${ }^{a}$ David C. Attrill, DDS, PhD, \\ and A. Damien Walmsley, DDS, PhD ${ }^{\mathrm{b}}$ \\ ${ }^{a}$ Department of Oral \& Maxillofacial Prosthodontics and Oral Implantology, University of Tokushima, Institute of \\ Health Biosciences, Tokushima, Japan \\ ${ }^{\mathrm{b}}$ School of Dentistry, The University of Birmingham, Birmingham, UK
}

\section{Clinical significance}

Teaching methods and processes were compared between a Japanese dental school and a UK dental school using the speciality of removable prosthodontics. This is useful for the sharing of ideas and concepts which may lead to improvements of educational standards.

\begin{abstract}
Purpose: The purpose of this study was to consider the possibility of undergraduate dental education improvement by comparing the dental courses in a Japanese dental school with a UK dental school using the speciality of removable prosthodontics.

Methods: Two dental schools, the University of Tokushima in Japan and the University of Birmingham in the United Kingdom, were compared. We compared both dental schools on the curriculum, lectures in removable prosthodontics, phantom head practice in removable prosthodontics, and clinical practice.

Results: There are large differences in undergraduate dental education courses between the two dental schools, especially in clinical practice. Clinical practice exposure in the University of Birmingham is more than three times as long as the University of Tokushima. The number of patients available for treatment in Birmingham is much more than Tokushima and the minimum requirements in removable prosthodontics in Birmingham is more than eight times as many as Tokushima.

Conclusion: Large differences in the undergraduate dental education courses between the two dental schools, including the number of patients for students,

Corresponding to: Dr Kan Nagao

Department of Oral \& Maxillofacial Prosthodontics and Oral Implantology, University of Tokushima, Institute of Health

Biosciences

3-18-15 Kuramoto, Tokushima 770-8504, Japan

Tel: +81-88-633-7347, Fax: +81-88-633-7461

E-mail:kan@dent.tokushima-u.ac.jp
\end{abstract}

Received on March 8, 2007 / Accepted on July 27, 2007 may be caused by the dental policy, the economy, religion and customs. It is important to execute education methods such as virtual reality simulation, ProblemBased Learning (PBL), Web-based courseware and Video-based self learning because of the lack of available patients in Japan.

Key words: undergraduate dental education, removable prosthodontics, United Kingdom and Japan

\section{Introduction}

As there are often differences in the way of dental education and curriculums around the world, it is useful to compare these between countries. Comparisons of teaching methods and processes enable the sharing of ideas and concepts which may be incorporated into the dental undergraduate curriculum within these countries, and this in turn will lead to improved standards. This concept has been explored at a European level with the formation of the Thematic projects DentEd and DentEd Evolves. ${ }^{1}$ These projects led to publications which provided an overall view on the provision of teaching not only within Europe, but also involved discussions with leading establishments in North America and Asia.

When educators have compared the undergraduate dental education taking place within different countries, they have focused on specific subject areas. Such an approach allows easy analysis of differences in the teaching and learning processes across institutions. The teaching of endodontics is one speciality that has been extensively reviewed globally. One study compared the pattern of teaching root canal therapy within dental schools of the UK with that carried out within several dental schools in Europe and USA. ${ }^{2}$ Preclinical endodontic teaching was 
compared within Europe, Scandinavia and North America. ${ }^{3}$ In contrast, another study compared endodontic courses and their treatment quality in Malmö, Sweden and Paris. ${ }^{4}$

There is an increasing trend within Europe towards the establishment of integrated restorative clinics where the specialities are combined and the students work within a general clinic where they provide integrated treatment for their patients. The values and practices of assessment of such clinics were investigated by a sample of teachers in restorative dentistry. ${ }^{5}$ The students and teachers valued the use of OSCEs, self-and peer-assessment, portfolio-based learning, feedback to students, objective criteria, communication skills and oral health education.

While most of the above articles were concerned with comparisons within Europe and North America, there are few reports which review the Teaching and Learning strategies within Japanese schools compared to other countries. The purpose of this study was to consider the plans to improve undergraduate dental education by comparing the dental courses in a Japanese dental school with a UK dental school using the speciality of removable prosthodontics. This will also lead to benchmarking standards between both dental schools.

\section{Materials and methods}

\section{Dental school}

Two dental schools, the University of Tokushima in Japan and the University of Birmingham in the United Kingdom, were compared. The School of Dentistry at the University of Tokushima is on Shikoku Island in the south of Japan (Web site address: - http://www.dent.tokushima-u.ac.jp/ english). It is a state funded school and has 330 students with approximately 55 per year. There are about 150 full time teaching staffs.

The School of Dentistry at the University of Birmingham is in the West Midlands region of the United Kingdom (web address: - http://www. dentistry.bham.ac.uk). There are 325 total students with 65 per year and there are 35 full time equivalent faculty members on the teaching staff (Table 1).

\section{The items to compare two dental schools}

We compared both dental schools on the following items:
Table 1 Comparison of number of students and staffs between the two schools.

\begin{tabular}{lcc}
\hline & Tokushima & Birmingham \\
\hline Duration of studying & 6 years & 5 years \\
\hline Students per year & 55 & 65 \\
\hline Full time teaching staffs & 150 & 35 \\
\hline
\end{tabular}

- Curriculum

- Lectures in removable prosthodontics

- Phantom head practice in removable prosthodontics

- Clinical practice (Integrated speciality teaching)

\section{Results}

\section{Curriculum}

The dental course in Tokushima is 6 years long and there is a $1 \frac{1}{2}$ year general human science course which is similar to a pre-dental course. The course in Birmingham has a duration of 5 years and the preclinical and clinical components are integrated. A comparison of the two courses is shown in Figure 1.

In our school, the student is expected to undertake $1 \frac{1}{2}$ years of Phantom head practice prior to the clinic, while in the UK this figure is half as long as Japan. Furthermore, in Birmingham there is greater clinical exposure in the integrated restorative clinic plus 1 year in the speciality clinic. Students provide basic restorative treatment such as periodontal prophylaxis and simple restorations before transferring their patients to the Prosthetics unit for removable prosthodontic treatment.

There are 2 full time faculties for clinical practice of removable prosthodontics in Tokushima while there are 3 in Birmingham. The structure and arrangements for teaching are similar in other departments.

\section{Lectures in removable prosthodontics}

Table 2 shows the difference in the lectures in removable prosthodontics between the two schools. Lecture times at Tokushima are 60 minutes in duration compared to approximately 45 minutes at Birmingham. The teaching unit of prosthodontics has a 30 minute small group tutorial before the clinics which is not present at Tokushima. There are approximately 18 timetabled small Group Tutorials that take place at Birmingham 


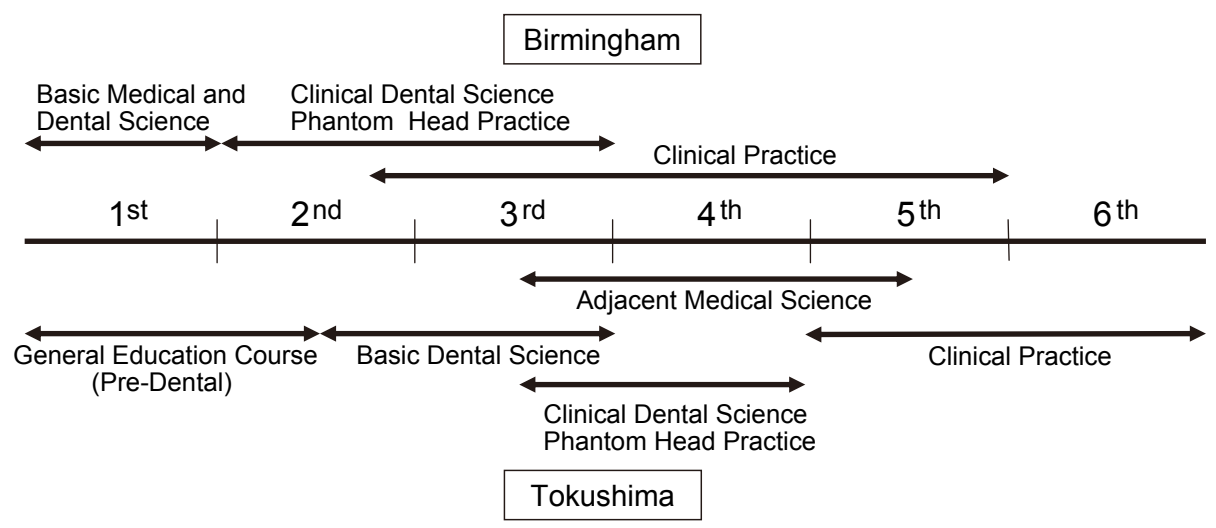

Fig. 1 Comparison of curriculum.

and cover a variety of topics which reinforce the lectures and introduce other concepts not normally given in the lectures.

\section{Phantom head practice in removable prosthodontics}

Table 3 shows the difference in the phantom head practice in removable prosthodontics between the two schools. Tokushima relies heavily on the use of instructors and has double the amount of laboratory time.

The number of students per instructor at Birmingham is two or three times as many as Tokushima. Furthermore, the number of laboratory contact hours in Tokushima is twice as many as Birmingham. UK dental schools are able to function with reduced dental instructors as the practical procedures involved are at a more basic level and there is not the same detail required.

The phantom head practice at Birmingham covers complete and partial wax dentures and is spread over a 3 term year. Term 6 (summer term year 2) consists of the manufacture of a simple acrylic guard for their own use. Part of the teaching consists of fracturing the acrylic plate and then repairing it. Terms 7 and 8 consist of the laboratory manufacture of partial and complete wax dentures respectively. In the phantom head course they undertake one complete case and one partial denture by themselves.

On the other hand, the phantom head practice at Tokushima covers complete and partial acrylic dentures. The first half consists of the laboratory manufacture of complete denture. Students investigate the wax denture, heat-curing and perfect acrylic complete dentures. The latter half consists of the manufacture of partial denture.
Table 2 Comparison of lecture in removable prosthodontics.

\begin{tabular}{ccc}
\hline & Tokushima & Birmingham \\
\hline Lectures & 30 times & 30 times \\
& $(60$ minutes $)$ & $(45$ minutes $)$ \\
& 30 hours & 22.5 hours \\
\hline Small Group Tutorials & & 18 times \\
& & $(30$ minutes $)$ \\
\hline Total & 30 hours & 31.5 hours \\
\hline
\end{tabular}

Table 3 Comparison of phantom head practice in removable prosthodontics.

\begin{tabular}{ccc}
\hline The number of students & Tokushima & Birmingham \\
\hline $\begin{array}{c}\text { Students per an } \\
\text { instructor }\end{array}$ & 55 & 70 \\
\hline Practice hours & $\begin{array}{c}30 \text { times } \\
(3.5 \text { hours }) \\
105 \text { hours }\end{array}$ & $\begin{array}{c}23 \text { times } \\
(2.5 \text { hous }) \\
57.5 \text { hours }\end{array}$ \\
\hline Requirements & $\begin{array}{c}\text { complete denture } \\
\text { partial denture } \\
\text { (acrylic denture) }\end{array}$ & $\begin{array}{c}\text { acrylic guard } \\
\text { partial denture } \\
\text { (wax denture) }\end{array}$ \\
\hline
\end{tabular}

\section{Clinical practice}

Table 4 shows the difference in the clinical practice between the two schools. The clinical teaching of students differs between the two schools and there are two important differences.

\section{- The clinical exposure}

The clinical exposure at the University of Birmingham is more than three times as long as the University of Tokushima.

The Junior Restorative Phase is established for 2 years and 3 months (from summer term year 2 
Table 4 Comparison of clinical practice in removable prosthodontics.

\begin{tabular}{ccc}
\hline & Tokushima & Birmingham \\
\hline Clinical exposure & 1.75 years* & 3.25 years \\
\hline Minimum requirement & 1 denture & 8 dentures \\
\hline Instructor & same & same \\
\hline Patient & 1 patient / student & many \\
\hline Contact with patient & rare & often \\
\hline
\end{tabular}

*6 months pre-clinical practice plus 3 months extra practice.

to term end year 4) in Birmingham and students treat their patients in the University Dental Hospital. The Senior General Dental Practice Phase is established for one year when students treat patients in a dental office (General Dental Practice Clinic).

In Tokushima University, the clinical practice is constituted and students treat their patients for one year. The pre-clinical practice is established for 6 months prior to the clinical practice, and students take some training to obtain the qualifications for treating their patients in the University Dental Hospital.

\section{- The number of patients and minimum requirements}

There are more patients available for treatment and the minimum requirements are higher at the University of Birmingham than Tokushima. A comparison of the number of patients that are treated in removable prosthodontics between the two establishments is as follows.

Within the speciality of prosthetics in the $\mathrm{Ju}^{-}$ nior Restorative Phase at Birmingham, the student must complete the clinical work for three patients requiring at least one full denture and one reline or rebase. They are also expected to complete at least 4 to 5 other patients in the Senior General Dental Practice Phase. They are only expected to undertake the laboratory support for one of their cases.

In Tokushima, the students undertake the treatment of 1 patient requiring partial and/or complete denture, and the teaching and learning system consists of observation of the staff treatment sessions on patients. The student is timetabled to observe for the full day. They will treat their patient under supervision. They also undertake substantial all laboratory work including the processing and making of the metal work (casting).

\section{Discussion}

Learning and teaching practices in the speciality of removable prosthodontics were compared between Japanese and UK dental schools. There are large differences in undergraduate dental education courses between the two dental schools, especially in the phantom head practice and the clinical practice.

The UK dental schools are able to function with reduced dental instructors in the phantom head practice. The phantom head practice at Birmingham covers a simple acrylic guard, repairing a fractured acrylic plate, and complete and partial wax dentures, while complete and partial acrylic dentures are covered at Tokushima.

The goal in phantom head practice at Birmingham is simple, as students are allowed to provide many dentures in clinical exposure. On the other hand, it is very difficult to recruit patients for students in Japan. Therefore, the goal in phantom head practice is harder and the Japanese dental schools have to send more instructors and spend more time than the UK.

The clinical exposure in Birmingham is more than three times as long as Tokushima University. Birmingham has embraced integrated whole patient care. Students commence treatment of patients at the end of year 2 . They provide simple treatment including plastic restorations and scaling and polishing together with other preventative treatments. They are allowed to provide simple immediate additions to removable dentures and repair broken dentures. They will provide the restorative treatment necessary before provision of a removable prosthetic in the prosthetic dentistry teaching unit. Therefore, both clinical practice and the teaching of prosthodontics are integrated. Patient treatment is provided free of charge except for the provision of dentures. The clinical teaching of prosthetics continues for one year during which they will provide 3 items of work and two simple extra items. In Birmingham, the long clinical exposure (more than three years) allows students the opportunity to meet the patients who accept their cooperation for the clinical practice and makes easy-to-integrate whole patient care.

On the other hand, although the clinical practice starts at the beginning of year 5 in Tokushima, students commence treatment of patients 6 months later. They are allowed to provide only one or two dentures, because it is very difficult 
to recruit the patients for students in Japan. Tokushima patients have to pay the same charge as regular patients notwithstanding the fact that they're supporting the clinical practice. This is mainly due to the fee system where no allowances or reductions are made for treatment within the school teaching clinics. The charges are the same as outside treatment and there is no difference between patient treatment provided by either the student or faculty.

In Tokushima, students have to spend a lot of time on phantom head practice which compensates for the unsatisfactory clinical practice because of few patients; therefore, the clinical exposure becomes increasingly short.

Differing measures and devices are executed because of few patients at the University of Tokushima such as substantial phantom head practice, virtual reality simulation ${ }^{6}$ and PBL. $^{7}$ At the University of Tokushima, there is a short duration of PBL where small groups of 7 to $8 \mathrm{stu}^{-}$ dents are provided with photographs, models and radiographs. The group is then encouraged to discuss the treatment planning of the case. There are many other methods of learning and teaching for undergraduate dental education and these include Web-based courseware, ${ }^{8-10}$ video-based ${ }^{11}$ and other multimedia programs. ${ }^{12}$ The treatment of patients is the best measure for advancement of students' skill, but it is very difficult because of few patients. Though many students always spend a great deal of time assisting instructors, it is not able to activate their motivation for learning. These alternative teaching methods can amuse the mass of students and it is necessary to try to execute these methods as compensation for the lack of patients. However, expensive equipment is required for these education systems.

\section{Conclusion}

There are large differences in undergraduate dental education courses between the two dental schools, especially the number of patients for students. These deviations are a result of many differences including government policy towards dentistry and variations in culture and philosophy. It is important to execute education methods such as virtual reality simulation, PBL, Webbased courseware and Video-based self learning because of the lack of available patients in $\mathrm{Ja}^{-}$ pan.

\section{References}

1. Scott J. Dental education in Europe: the challenges of variety. J Dent Educ 2003; 67: 69-78.

2. Dummer PM. Comparison of undergraduate endodontic teaching programmes in the United Kingdom and in some dental schools in Europe and the United States. Int Endod J 1991; 24: 169-177.

3. Qualtrough AJ, Whitworth JM, Dummer PM. Preclinical endodontology: an international comparison. Int Endod J 1999; 32: 406-414.

4. Petersson K, Olsson H, Soderstrom C et al. Undergraduate education in endodontology at two $\mathrm{Eu}^{-}$ ropean dental schools. A comparison between the Faculty of Odontology, Malmo University, Malmo, Sweden and Faculty of Odontology, Paris 5 University (Rene Descartes), France. Eur J Dent Educ 2002; 6: 176-181.

5. Manogue M, Brown G, Foster H. Clinical assessment of dental students: values and practices of teachers in restorative dentistry. Med Educ 2001; 35: 364-370.

6. Quinn F, Keogh P, McDonald A et al. A study comparing the effectiveness of conventional training and virtual reality simulation in the skills acquisition of junior dental students. Eur J Dent Educ 2003; 7: 164-169.

7. Pau AKH, Croucher R. The use of PBL to facilitate the development of professional attributes in second year dental students. Eur J Dent Educ 2003; 7: 123-129.

8. Eynon R, Perryer G, Walmsley AD. Dental undergraduate expectations and opinions of Web-based courseware to supplement traditional teaching methods. Eur J Dent Educ 2003; 7: 103-110.

9. Walmsley AD, White DA, Eynon R et al. The use of the Internet within a dental school. Eur J Dent Educ 2003; 7: 27-33.

10. Corrêa L, de Campos AC, Souza SC. Teaching oral surgery to undergraduate students: a pilot study using a Web-based practical course. Eur J Dent Educ 2003; 7: 111-115.

11. Kalwitzki M, Rosendahl R, Gottle R et al. Acceptance of video-based teaching in paediatric dentistry by undergraduate dental students. Eur J Dent Educ 2003; 7: 66-71.

12. Packer ME, Coward TJ, Wakeley R et al. A preliminary study to investigate the potential of plasma screen technology in small group teaching for dental undergraduates. Eur J Dent Educ 2003; 7: 136-142. 